\title{
Stream Restoration in the Upper Midwest, U.S.A.
}

\author{
Gretchen G. Alexander ${ }^{1}$ and J. David Allan ${ }^{1,2}$
}

\begin{abstract}
Restoration activities intended to improve the condition of streams and rivers are widespread throughout the Upper Midwest, U.S.A. As with other regions, however, little information exists regarding types of activities and their effectiveness. We developed a database of 1,345 stream restoration projects implemented from the years 1970 to 2004 for the states of Michigan, Ohio, and Wisconsin in order to analyze regional trends in goals, presence of monitoring, spatial distribution, size, and cost of river restoration projects. We found that data on individual projects were fragmented across multiple federal, state, and county agencies, as well as nonprofit groups and consulting firms. The most common restoration goals reported for this region were in-stream habitat improvement, bank stabilization, water-quality management, and dam removal. The former two were most common in Michigan and Wisconsin, where salmonid fisheries enhancement appeared to be an important concern, whereas
\end{abstract}

water-quality management was most frequent in Ohio. The most common restoration activities were the use of sand traps and riprap, and other common activities were related to the improvement of fish habitat. The median cost was $\$ 12,957$ for projects with cost data, and total expenditures since 1990 were estimated at $\$ 444$ million. Over time, the cost of individual projects has increased, whereas the median size has decreased, suggesting that restoration resources are being spent on smaller, more localized, and more expensive projects. Only $11 \%$ of data records indicated that monitoring was performed, and more expensive projects were more likely to be monitored. Standardization of monitoring and record keeping and dissemination of findings are urgently needed to ensure that dollars are well spent and restoration effectiveness is maximized.

Key words: ecosystem management, monitoring, restoration, stream improvement, watershed.

\section{Introduction}

Aquatic ecosystems are being impaired by human activities worldwide (Gleick 2003). In the Upper Midwest region of the United States, shifts in land use toward agricultural and urban development in the last century have contributed to the deterioration of many waterways. In agricultural settings, river ecosystems have experienced increased nutrient and sediment loads (Oberle \& Burkart 1994), altered flows (Poff et al. 1997), and habitat degradation (Roth et al. 1996), whereas in urban settings, impervious surfaces and infrastructural constraints on rivers have led to the introduction of chemical pollutants, altered flows, and system instability (Oberle \& Burkart 1994; Doyle et al. 2000; Davis et al. 2003; Murdock et al. 2004). Fragmentation of river ecosystems by dams has further degraded lotic environments (Bednarek 2001; Stanley \& Doyle 2003). Consequently, stream restoration is emerging as an important approach for addressing water resources issues. Restoration projects can be viewed as applied experiments of ecological knowledge (Michener 1997). However, because stream restoration projects rarely are implemented within an experimental context or receive pre- and postproject evaluations, little information exists

\footnotetext{
${ }^{1}$ School of Natural Resources \& Environment, University of Michigan, Ann Arbor, MI 48109-1041, U.S.A.

${ }^{2}$ Address correspondence to J. David Allan, email dallan@umich.edu

(C) 2006 Society for Ecological Restoration International
}

on the effectiveness of commonly used stream restoration practices (Kondolf \& Micheli 1995; Moerke \& Lamberti 2004).

An important step in furthering the science of stream restoration is to examine existing restoration projects and their methods and outcomes. The National River Restoration Science Synthesis (NRRSS) reported findings from a database of 37,000 stream and river restoration projects from around the nation, organized around 13 restoration goals identified a priori (Bernhardt et al. 2005). Most projects were of small scale $(<1.5 \mathrm{~km}$ in length) and were obtained from national databases and by intensive data gathering in seven geographic regions of the United States. Nationally, the most common goals were to enhance water quality, manage riparian zones, improve in-stream habitat, and for fish passage and bank stabilization. Although stream restoration activities have increased dramatically, and now account for annual expenditures in excess of $\$ 1$ billion nationwide, Bernhardt et al. (2005) found that data reporting was very limited, monitoring was reported in only $10 \%$ of projects, and the evaluation and dissemination of success were inadequate.

Here we report an in-depth analysis of the results of 1,345 projects from the states of Michigan, Wisconsin, and Ohio. We characterize stream restoration activities within the Upper Midwest region, highlight strengths and weaknesses of these approaches, and make recommendations to further the science of stream restoration within the region. Analyses of this database provide a regional 
perspective regarding the types of restoration being conducted, the number and spatial extent of projects implemented, and expenditures on restoration activities.

\section{Methods}

The study area included Michigan, Ohio, and Wisconsin in the Upper Midwest, U.S.A. In general, the northern regions of the study area are characterized as forested and rural, whereas the southern regions are more agricultural and urbanized (Albert 1995). These states were known to be active in stream restoration and were expected to encompass a range of project activities, therefore providing an understanding of all types of stream restoration occurring in the Upper Midwest region.

Information on stream restoration in the Upper Midwest was collected from many sources as part of the NRRSS. At the national level, data were collected from the following federal agencies: Army Corps of Engineers, U.S. Fish and Wildlife Service, National Marine Fisheries Service, National Oceanic and Atmospheric Administration, and the United States Environmental Protection Agency (Jenkinson et al. 2006). We also contacted Departments of Natural Resources and Environmental Regulatory Agencies of the three states, as well as watershed groups, drain commissioners (Michigan), local governments, consulting firms, and nonprofit groups such as Trout Unlimited that are involved in stream restoration practices. We collected data via phone, e-mail, and mailings. Individuals contacted via e-mail were asked to fill out a form requesting descriptive information about as many restoration projects as they had knowledge. A similar request was sent out via mail for those contacts who did not have an e-mail address. When a phone number was available, individuals who did not respond received a follow-up call to encourage a response. In addition to personal contacts, data were collected via Web sites, via agency files, and from published documents. Because few records could be located for projects implemented earlier in time, only projects implemented between 1970 and 2004 were entered into the database to provide a standard time frame.

Data collection was not restricted to any specific definition of the term "stream restoration" because we wished to document how dollars and efforts are expended in the name of restoration. Therefore, if a project was identified as stream restoration by the project implementor, it was included in the database. If the term "restoration" did not appear in a project description and whether to include a project was ambiguous, we used a dichotomous key developed by the NRRSS working group to ensure that restoration was the primary purpose (Bernhardt et al. 2005). We collected descriptive information including restoration project name, stream name, project location (watershed, county, town, state, geographic coordinates), year of project permitting, year of implementation, year of completion, project contact name, affiliation, phone number and e-mail address, project size (area and length), project cost, presence of monitoring, monitoring focus, funder information, implementer information, presence of mitigation, data source type, project intent, and project activities. Data entry for the summary database was calibrated at the national project level and facilitated by the creation of a web-accessible data entry interface (Bernhardt et al. 2005).

We were careful to distinguish between project goals and activities. For example, bank revegetation (an activity) could be to meet the goal of bank stabilization, waterquality management, or an accompaniment to channel reconfiguration. Similarly, bank stabilization (a goal) could be met by bank revegetation, livestock exclusion, or physical grading (all activities). To distinguish between project goals and activities, 13 goal categories were determined a priori with descriptive metadata, and each project was classified into one or more of the 13 categories according to its stated goals (Bernhardt et al. 2005). Projects were assigned a category only if project goals were specified in the original data record and were never inferred from activities.

The database was culled for duplicates by searching for projects with similar stream names, project names, project locations, dates of implementation, and project goals and activities. Projects that shared these attributes were combined into a single record. Data collection ceased when all known data sources had been adequately pursued and the data were considered representative of the population of stream restoration projects within the region. Representativeness was determined by a final inspection of the data by knowledgeable professionals from each state. These individuals received a summary of the data by spatial extent, distribution of project goals, and sources of information. The summary data for each state included a map of the distribution of projects by county, a bar chart of the five most common project goal categories in the state, and a list of all data sources accessed and people contacted within the state.

Statistical data analysis consisted of a two-sample $t$ test on project cost and presence of monitoring. The test did not require any transformations of the data.

\section{Natural Resources Conservation Service Projects}

Stream improvement implemented through Natural Resources Conservation Service (NRCS) programs is known to be extensive, but available databases provided only county-level aggregated reports on NRCS conservation practices in each state. We considered it impractical to collect data for individual NRCS projects because this information is stored (usually as paper files) in individual county offices (approximately 205 for the three states). The inability to add NRCS projects to our database is a limitation of our study. 
Because agriculture is such a prominent land use within the study region, we sought other means to approximate the scope of NRCS-sponsored conservation practices with potential positive impacts to streams. The Farm Service Agency (FSA) database contained information on conservation practices implemented in every county in every state through the Conservation Reserve Enhancement Program/ Conservation Reserve Program (CREP/CRP). The three conservation practices summarized in this database that were relevant to stream restoration (due to their close proximity to streams) were filter strips, riparian buffers, and wetland restoration. Implementation of these conservation practices through the CREP/CRP program began in the late 1990s. Available information included total acres, dollars spent, and number of landowner contracts of each conservation practice organized by county. A Geographical Information System (GIS) was used to map the geographical distribution of these conservation practices within the study region, and the total dollars were summed to estimate the total cost of conservation practices related to stream restoration.

\section{Results}

\section{The Database}

The total number of projects in the Upper Midwest database was 1,345. Expert opinion provided support that, except for NRCS projects, data were representative both spatially and by goal, and there was no indication that existing data sources had been overlooked. However, examination of project distribution by county revealed that regions within the study area where the primary land use was agricultural were under-represented, and projects were disproportionately concentrated in northern regions (Fig. 1A), which likely reflects our inability to access records for agriculturally related stream restoration accomplished through the
NRCS. Comparing the spatial distribution of NRCS conservation projects (Fig. 1B) to the spatial distribution of individual stream restoration projects in our database, it is evident that the NRCS is engaged in considerable activity relevant to stream restoration in agricultural regions.

The number of stream restoration projects implemented in the study area has increased steadily over time (Fig. 2). Both the number of project records in the NRRSS database and the number of popular press articles that reference the topic of stream restoration show a steep upward trend. This trend may reflect greater availability of information about more recent projects, a tendency for the term "restoration" to supplant other terms such as improvement or management, as well as an actual increase in project implementation.

\section{Distribution of Project Goals}

In-stream habitat improvement and bank stabilization are the two most common project goals in these three Midwestern states, followed by water-quality management, dam removal/retrofit, and channel reconfiguration (Table 1). However, just over half of the projects were from a Michigan database, which classified all projects into only the two goals of in-stream habitat improvement and bank stabilization. When goals were examined by state, Michigan and Wisconsin were similar in being dominated by in-stream habitat improvement, whereas Ohio's most dominant project type was water-quality management (Table 1). This may reflect a management emphasis on coldwater fisheries enhancement in Michigan and Wisconsin, whereas Ohio Environmental Protection Agency (EPA) is particularly active with EPA 319 grants focused on water-quality issues.

Over 58 different types of stream restoration activities (actions implemented to carry out goals) were reported in
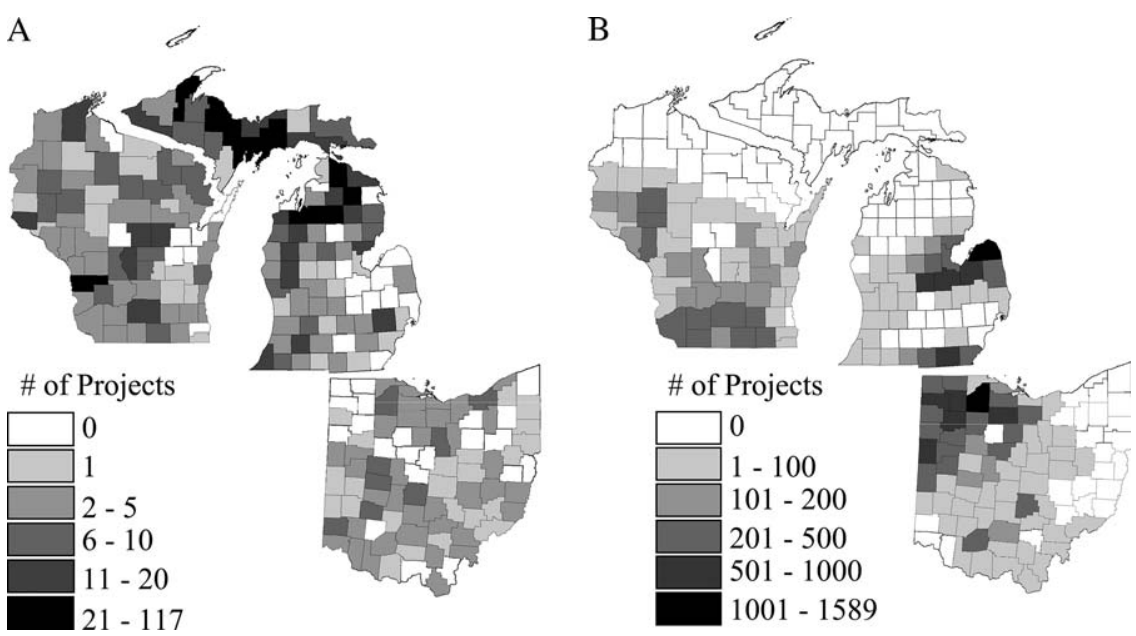

Figure 1. (A) Spatial distribution of stream restoration projects in the NRRSS Summary database. (B) Spatial distribution of conservation practices relevant to stream restoration implemented through the NRCS CREP/CRP program. Data are summarized by county. 


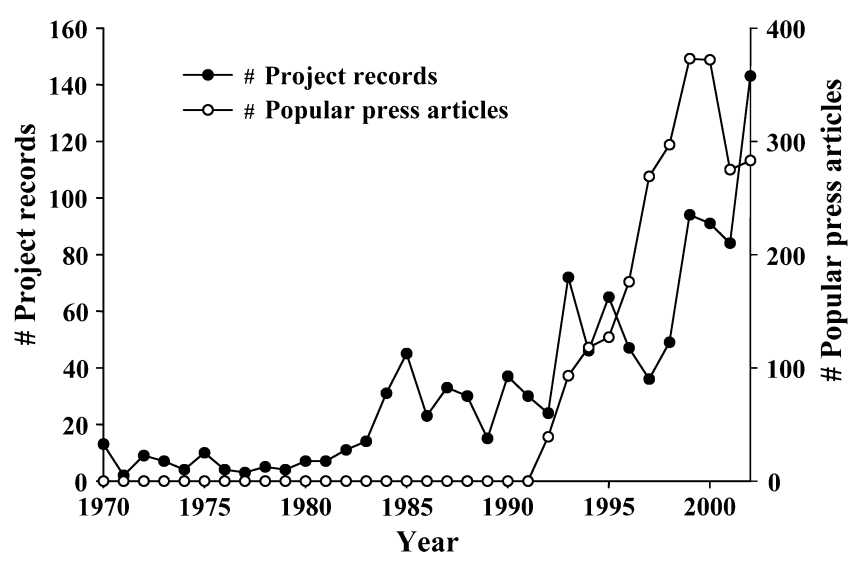

Figure 2. Number of stream restoration projects recorded in the NRRSS database in the Upper Midwest region (closed circles) and incidence of stream restoration in the Upper Midwest as reported in the popular press over time (open circles). Some $16 \%$ of the projects have no information on year of implementation, and so $n=1,095$ for this graph. Popular press citations were generated by searching the LexisNexis database for the search term "restoration and (stream or river)" for the years 1970-2002 for the states of Michigan, Ohio, and Wisconsin.

the Upper Midwest database. Parallel to the finding that in-stream habitat improvement was the most common goal reported, stream restoration activities in the study region were largely focused on in-stream habitat improvement. The most common activities in the Upper Midwest study region were the use of sand traps and riprap (Fig. 3), and three of the top five activities were directly related to the improvement of fish habitat (sand traps, addition of large woody debris [LWD], and Lunker structures). Sand traps are widely used by the Michigan Department of Natural Resources to remove excess sediment from streams, thus preventing its embedment in spawning gravels used by salmonids (Steen 2003). Suspended sand settles into a depression dug into the stream channel, and the deposited sediment is subsequently removed, requiring excavation with machinery. LWD is placed in streams to provide cover and habitat complexity for fish and other aquatic organisms (Shields et al. 2003). A Lunker is a crib-like structure placed in streams to provide bank stability and cover for fish (Hunt 1988).
The remainder of the 20 most common restoration activities represents a diversity of restoration actions and presumably of goals. Eight of the remaining most common restoration activities involved the placement of structures directly into or adjacent to the stream channel. Other common activities included the reshaping of channels through riffle and meander creation, as well as grading of streambanks. Riparian activities such as fencing to exclude cattle and maintaining buffer strips or removing non-native brush also were common.

\section{Monitoring}

Overall, only $11 \%$ of project records reported any monitoring. However, it is not known whether this indicates scarcity of monitoring or inadequate reporting. Of the five most frequent goal categories, monitoring was most cited in the category of water-quality management, where $33 \%$ of projects were monitored (Table 2). Conversely, reports of monitoring activities were lowest for in-stream habitat improvements and bank stabilization, which, as the most common project goals, contributed to the low overall value. Projects that were monitored were more expensive on average than unmonitored projects (Fig. 4). Although this was not a statistically significant result $(p=0.07)$, the lack of projects that reported monitoring and cost data together (just 67 projects out of the total 1,345) limited the statistical analyses.

\section{Size and Cost of Restoration}

The total cost of all projects in the Upper Midwest region for those with cost information included in data records $(n=400)$ was $\$ 75,642,874$ for the 13 -year period of 1990 2003 (Table 3). The median project cost was $\$ 12,957$. This estimate does not take into account projects for which no cost data were provided, and it does not include NRCS projects; however, we can approximate the missing cost information.

To correct for projects in the Upper Midwest database that lacked cost data, we extrapolated the total cost obtained for the $47 \%$ of projects with cost information to the project total (Alexander 2005). This increased the tristate total to $\$ 160$ million, or a yearly average of $\$ 12.3$

Table 1. Relative occurrence by state of the six most common stream restoration project goals in the Upper Midwest.

\begin{tabular}{lcrrr}
\hline & Michigan & Wisconsin & Ohio & Total \\
\hline In-stream habitat improvement (\%) & 67 & 58 & 8 \\
Bank stabilization (\%) & 47 & 8 & 33 \\
Water quality (\%) & 2 & 6 & 38 \\
Dam removal (\%) & 2 & 22 & 2 & 7 \\
Channel reconfiguration (\%) & 1 & 10 & 5 \\
Riparian management (\%) & 0 & 5 & 9 \\
\hline
\end{tabular}

Values represent the percentage of projects per state and the tristate total for each specified project goal. Some $24 \%$ of the projects listed more than one goal, resulting in the number of listed project goals exceeding the number of projects. 


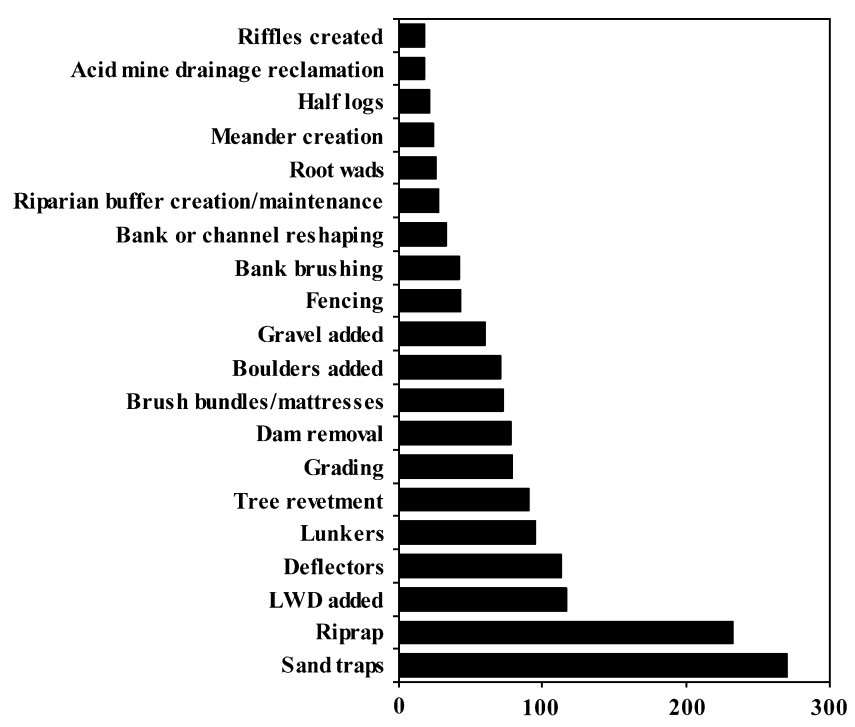

Figure 3. The 20 most common project activities listed in the NRRSS Summary database for the Upper Midwest region. The number of projects that reported each activity is shown on the horizontal axis. Use of sand traps and riprap stand out as the dominant techniques used in stream restoration in the Upper Midwest region.

million. Projects in the water-quality management category were estimated to account for almost $\$ 60$ million of the total cost and had the highest median cost of $\$ 234,500$ (Table 2) but accounted for only $6.5 \%$ of the number of projects with cost information. Conversely, projects in the in-stream habitat improvement category were estimated to account for just $\$ 25$ million in total project costs, yet these types of projects comprised $48 \%$ of all projects in the database with cost information (Fig.5). A separate accounting for the year 2002, the most recent year for which cost data were most complete, estimated that at least \$22.1 million was spent in the Upper Midwest study region. This higher estimate for the year 2002, when compared with the average estimated for 1990-2002, is consis- tent with the increasing amount of restoration activity in recent years (Fig. 2), as well an increased implementation over time of more expensive project types, such as waterquality management.

To estimate the dollars spent on restoration activities by the NRCS, we used cost data for the selected conservation practices listed in the CREP/CRP database. The NRCS expenditures for these three stream-related practices (filter strips, riparian buffers, and wetland restoration) totaled \$283 million for 1997-2004 and represented 26,573 separate implementations of these conservation practices. Bearing in mind that the three listed conservation practices represent only a subset of practices that may positively affect streams, and that these data represent just one of the NRCS conservation practice programs, it is evident that the monetary contribution of the NRCS to stream restoration in the study region is considerable. Combining the estimate from the NRRSS database and the NRCS county-level information indicates that the true cost of implementing stream restoration practices in the study region since 1990 was roughly $\$ 444$ million. Thus, the estimate of total cost of stream restoration in the study area was more than doubled when NRCS conservation practices were considered.

Over time, the median cost of individual restoration projects in the NRRSS database increased, whereas the median size of individual restoration projects decreased (Fig. 6). The mean cost increased much more than the median cost, indicating that the mean is skewed owing to a relatively small number of expensive projects. When mean project size (length) is multiplied by the number of projects without size information and added to the total size of all projects with size information, the estimated total length of stream restored in the Upper Midwest from 1970 to 2002 is close to $9,677 \mathrm{~km}$ or 6,000 miles (Table 3), approximately $5 \%$ of the total stream length in the study area. An evaluation of the percentage of large projects over time, those that restore more than $1.5 \mathrm{~km}$ of stream, also indicates a decreasing trend $\left(r^{2}=0.55\right)$ (Fig. 7). The

Table 2. Number of projects, percent monitored, and median cost of projects by goal category.

\begin{tabular}{|c|c|c|c|}
\hline NRRSS Goal Category & No. of Projects & Percent Monitored & Median Cost (\$) \\
\hline Bank stabilization (BS) & 489 & 4 & 5,000 \\
\hline Dam removal/retrofit (DR/R) & 94 & 18 & 95,000 \\
\hline Fish passage (FP) & 14 & 21 & 28,250 \\
\hline Floodplain reconnection $(\mathrm{FR})$ & 3 & 67 & 37,000 \\
\hline In-stream species management (ISM) & 9 & 33 & 3,500 \\
\hline Land acquisition (LA) & 5 & 0 & 160,000 \\
\hline Riparian management (RM) & 37 & 22 & 10,835 \\
\hline Stormwater management (SM) & 5 & 0 & 85,050 \\
\hline Water-quality management (WQM) & 108 & 33 & 234,500 \\
\hline
\end{tabular}

Some $24 \%$ of the projects listed more than one project goal. In total, $11 \%$ of the project records indicated that some type of monitoring was performed. 


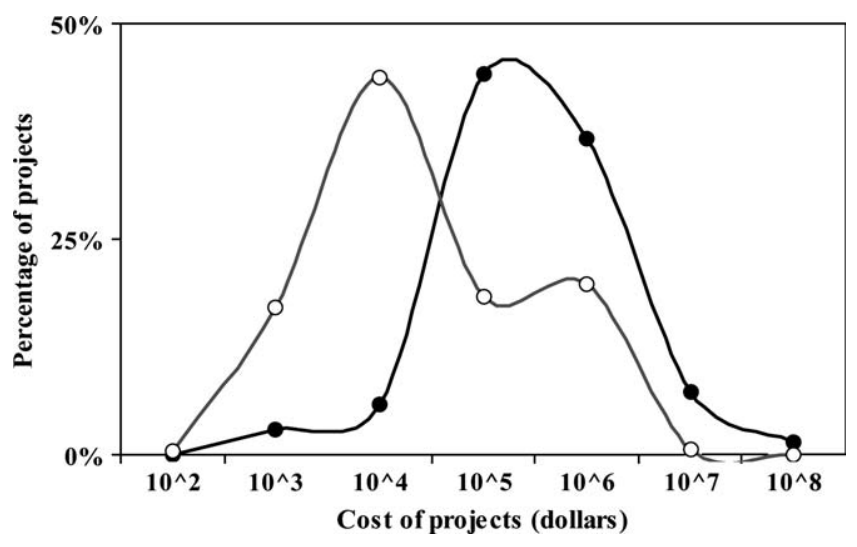

Figure 4. Distribution of costs of monitored (closed circles) and unmonitored (open circles) projects. Bin labels represent upper limit. The mean project cost of monitored projects $(\$ 621,282, n=67)$ is higher than the mean project cost of unmonitored projects $(\$ 89,700$, $n=565)$.

upward project cost and downward project size trends together suggest that over time, more resources are being spent on smaller, more localized, and more expensive projects.

\section{Discussion}

The incidence of stream restoration documented in the popular press has increased steadily within the study region since the early 1990s, in parallel with the increase over time in the number of stream restoration projects in the Upper Midwest database. This may reflect an actual increase in project implementation, but it also may result from a greater availability of information about recent projects. It is also possible that this apparent rise in the number of implemented projects reflects a shift in the ways that projects are reported. For example, the large number of projects listing the use of riprap as an activity, combined with the small size and cost of most projects, may reflect an increasing tendency to refer to these types of projects as restoration rather than as channel stabilization. If this is the case, projects with the potential to be ecologically harmful may increasingly be implemented under the guise of restoration. Nonetheless, despite other possible explanations for this rising trend, the growing lit- erature (both popular and scientific) on the topic of stream restoration reveals an increasing focus on the use of the term restoration and its associated practices (Bernhardt et al. 2005).

Although the database of 1,345 projects from Michigan, Wisconsin, and Ohio is the most comprehensive listing of stream restoration in the Upper Midwest, its limitations must be acknowledged. Regional experts judged the database to be representative of the region; however, we cannot establish if projects were overlooked, and even the most useful data records often provided less information than would be desirable. Most seriously, the limited interpretability of NRCS conservation practices relevant to stream restoration was a significant impediment. Therefore, estimates of total cost and other descriptors are conservative and only the first step toward a full understanding of the scope of restoration practices.

Habitat improvement, bank stabilization, and waterquality management are the dominant project goals identified in our database for the Upper Midwest, with a greater emphasis on water-quality issues in Ohio. We think these trends are broadly valid, with two caveats. First, data from Michigan DNR reported only the two goals of habitat improvement and bank stabilization; however, this reflected the viewpoint of professionals that most restoration activities had these two goals. In addition, data from Wisconsin, which included more categories, were similar in that in-stream habitat improvement was the most common goal. Second, NRCS projects were excluded from our database because they are reported only as county totals, not as individual cases. Because the vast majority of these involve plantings and land retirement, their inclusion likely would result in a considerably higher proportion of projects with the goal of riparian management, which was one of the most common goals reported in the national database (Bernhardt et al. 2005) but infrequent in the Midwest database.

Project activities were extremely diverse. The most common activities were those that took place within the stream channel or along the banks, which would be expected from the most common stated goals. Additional activities associated with riparian plantings would be expected if NRCS projects were included.

Many authors have stressed the importance of monitoring as part of the learning cycle and to practice adaptive

Table 3. Size and cost of stream restoration projects in the NRRSS database for the Upper Midwest region.

\begin{tabular}{|c|c|c|c|c|}
\hline & $\begin{array}{c}\text { Total for All Projects } \\
\text { with Data }\end{array}$ & $\begin{array}{c}\text { Extrapolated Total for } \\
\text { All Projects }\end{array}$ & $\begin{array}{c}\text { Mean for All Projects } \\
\text { with Data }\end{array}$ & $\begin{array}{c}\text { Median for All Projects } \\
\text { with Data }\end{array}$ \\
\hline Project length (miles) & $1,842.50^{a}$ & $5,763.16$ & $4.28^{a}$ & $0.26^{a}$ \\
\hline
\end{tabular}

Extrapolated totals were calculated by multiplying average values by the number of projects with missing data.

${ }^{a} n=430$.

${ }^{b}$ Cost estimates are based on data from the years 1990-2003.

${ }^{c} n=400$. 


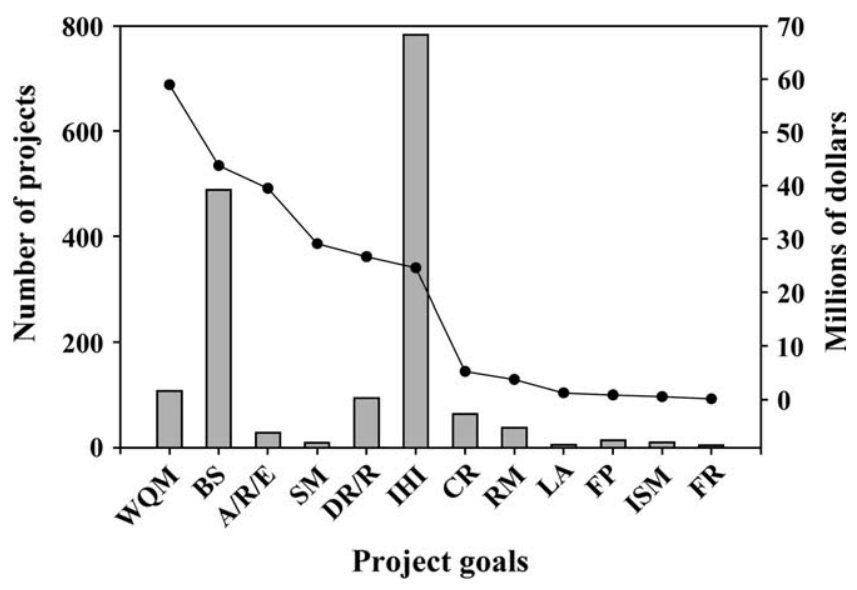

Figure 5. Number of projects and extrapolated cumulative costs of restoration projects (see Table 2 for key to goals). Gray bars represent the number of projects in a goal category, and the closed circles and line represent the extrapolated cumulative cost of projects in \$U.S. in each goal category.

management (Downs \& Kondolf 2002; Jungwirth et al. 2002; Palmer et al. 2005). Monitoring or evaluation occurred in approximately $10 \%$ of the projects in the national database and was more likely to occur in more expensive projects (Bernhardt et al. 2005). We likewise found a similarly low rate of monitoring in our Upper Midwest database $(11 \%)$ and a tendency for greater frequency of monitoring associated with more expensive projects. Our finding that monitoring was greatest in the category of water-quality management may be due to the relative ease of water-quality monitoring using well-established and widely known protocols. The fact that habitat improvements and bank stabilization are so commonly implemented may favor a low monitoring rate.

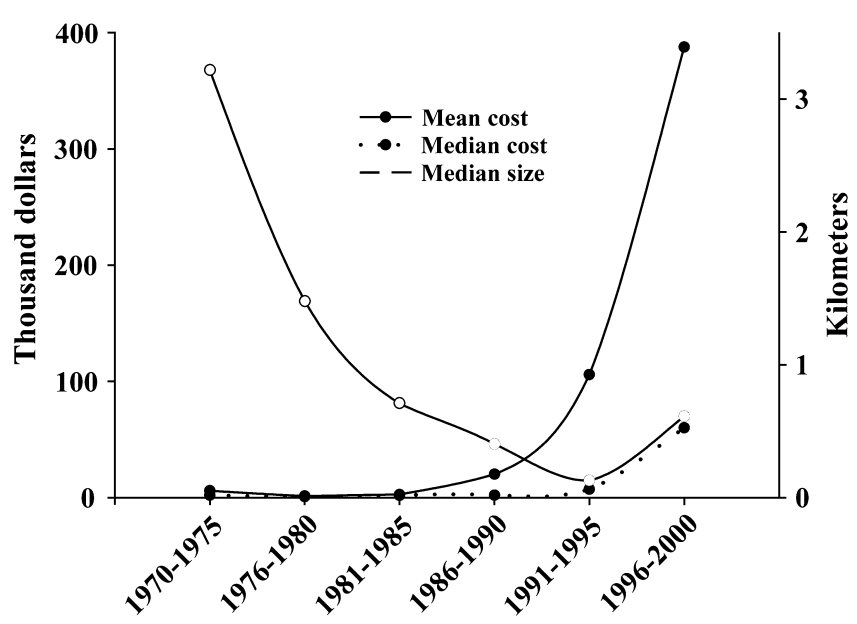

Figure 6. Mean (solid circles) and median (solid circles, dotted line) cost of restoration projects, and median length in kilometers (open circles) of projects over time. Means and medians were calculated over 5-year increments starting in 1970. For costs, $n=633$; for length, $n=430$.

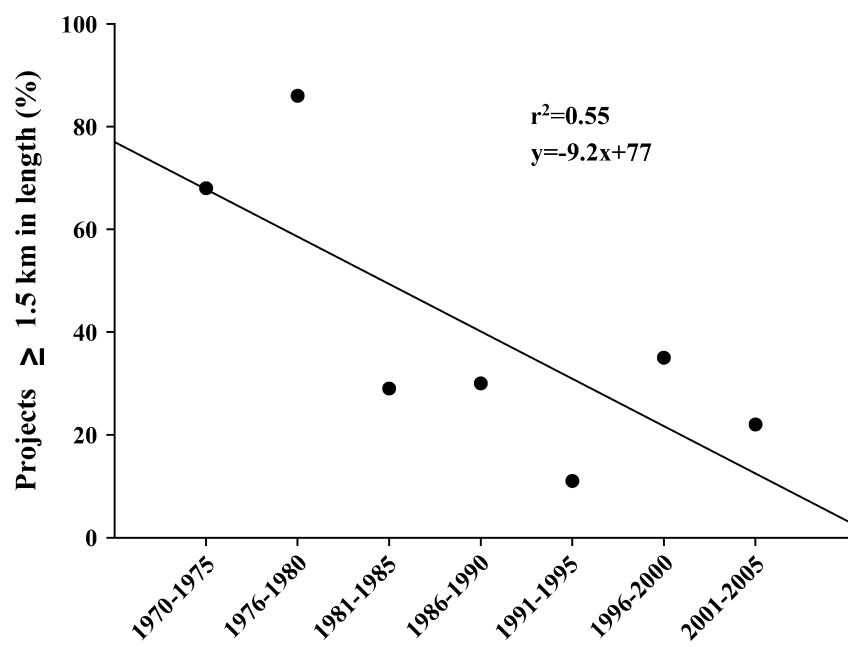

Figure 7. The percentage of stream restoration projects greater than or equal to $1.5 \mathrm{~km}$ in length, shown at 5-year intervals starting in 1970.

In-depth interviews may reveal a greater frequency of monitoring than revealed by the NRRSS database, where project records often contained minimal information. Questionnaires and thorough surveys of 10 restoration projects in Indiana (Moerke \& Lamberti 2004) revealed that fewer than half conducted pre- or postproject evaluations, a lower rate than we found. Our own surveys of 39 projects from within the NRRSS database found that roughly three quarters had some form of monitoring, although often of limited scope (Alexander 2005).

The circumstances under which monitoring should be pursued, or might be considered unnecessary, are inadequately known, but it is reasonable to expect that monitoring may become less needed over time as experience provides confidence in outcomes. For example, the state of Wisconsin has studied the success of in-stream habitat improvements implemented by the Wisconsin DNR since the early 1950s (Hunt 1988; Avery 2004). These authors compiled case studies of more than 45 in-stream habitat projects throughout the state of Wisconsin and reported on the effectiveness of the techniques used in enhancing fish communities. The large number of compiled case studies investigating the ecological success of common restoration practices has allowed resource managers within the region to implement in-stream habitat improvement projects with reasonable confidence that their actions will result in increased fish populations. The compiling of case studies of specific types of restoration actions within a regional context should be encouraged as a means to accurately predict ecological responses and further the science of stream restoration. As we learn more about the success of certain restoration practices, the need for the monitoring of such projects may be lessened.

Bernhardt et al. (2005) estimated the annual cost of stream restoration in the United States at in-excess of $\$ 1$ billion, and acknowledged this was likely an 
underestimate because it excluded in-kind contributions such as labor by partner agencies, as well as very large projects such as the Everglades. Our estimate for the Upper Midwest of \$22.1 million for 2002 was obtained by a comparable analysis and suggests that the Upper Midwest contributed only about $2 \%$ of the national total. This is unsurprising because the national estimate using the NRRSS database was strongly influenced by the disproportionately greater number of projects in the Pacific Northwest, the Chesapeake Bay region, and California. However, it should also be noted that NRCS projects were not included by Bernhardt et al. in the estimation of restoration dollars spent. Based on our approximations of the NRCS expenditures related to stream restoration ( $\$ 283$ million since 1997), dollars spent under NRCS conservation activities more than equal those captured in the NRRSS database for the Upper Midwest. Similar to another regional summary of NRRSS findings in the Chesapeake Bay Watershed (Hassett et al. 2005), water-quality management projects stood out as being highest in cost but relatively few in numbers. A possible explanation for this trend in the Upper Midwest region is that many of the projects with the goal of water-quality improvement were federally funded and expensive projects (approximately $\$ 200,000$ ) that addressed water-quality issues at the scale of the watershed over multiple years.

Just what is accomplished as a consequence of these substantial expenditures clearly deserves more study. We conservatively estimate that restoration and conservation activities have influenced nearly $10,000 \mathrm{~km}$ of stream in these three states, or roughly $5 \%$ of total stream length, thus positive ecological effects should be demonstrable.

We found a tendency for individual projects to be come both costlier and smaller in size over time. Two possible explanations deserve consideration. Certain types of projects, such as stormwater management, channel reconfiguration, and dam removal, have become more common in recent years, and these are both costly and localized. In addition, there is some indication that because models, GIS, and existing databases have become more commonplace, and regulatory standards play a larger role, watershed professionals appear to be focusing on smaller units of study where problems are more definable, solutions more readily implemented, and outcomes at least in principle more easily demonstrated. In a review of nearly 800 papers published in the conference proceedings of Water Environment Federation between 1993 and 2004, Freedman et al. (2004) reported that practices have become more scientific and technical but also less holistic. Our finding that over time, greater amounts of money are being spent on increasingly smaller projects likely is evidence that the tendency toward more technical and localized projects holds true for the Upper Midwest region. However, whether individual projects are being implemented within a holistic watershed perspective is not answerable with our data.
The increased focus on river restoration reflects a growing awareness of the need to practice whole-watershed management to address the loss of ecosystem goods and services (Wissmar \& Beschta 1998; Bohn \& Kershner 2002; Covich et al. 2004). Despite widespread advocacy of holistic approaches such as integrated river basin management (IRBM), considerable uncertainty remains with respect to its definition and, most importantly, its implementation (Global Water Partnership 2000; Gilman et al. 2004). Broader ecological goals often are addressed in better examples of IRBM (Gilman et al. 2004), although typically this reflects a concern for the protection of ecosystem processes (hydrologic regime, water quality) that also benefit humans. Direct planning based on conservation and restoration considerations is less common.

Single-focus restoration projects, such as improving a fishery, remain common but are ecologically limited because they fail to take an ecosystem perspective (Roper et al. 1997; Laasonen et al. 1998). In such instances, fish habitat installations are done with the expectation that the creation of habitat will result in increased numbers of fish. However, the assumption that ecosystem function will return as a result of the creation of an organism's habitat is ill founded if in-stream habitat is not the organism's limiting factor within the environment (Larson et al. 2001; Pretty et al. 2003; Cowx \& de Jong 2004). For example, Pretty et al. (2003) attributed the failure of an in-stream habitat project to the observation that, without first improving water quality at the site, installation of LWD would not be expected to have a positive effect on fish populations. However, diagnosis of the limiting factor of streams has been a suggested management strategy in Wisconsin since the 1960s (White \& Brynildson 1967; Lyons \& Courtney 1990), and so the habitat improvement projects carried out by the Wisconsin Department of Natural Resources are done with substantial knowledge of environmental impacts at the watershed level. Thus, it may be feasible to have a primary goal, such as salmonid enhancement, and pursue it within a more holistic framework.

In summary, our database of 1,345 restoration projects from the Upper Midwest indicates that stream restoration is widespread, diverse, and involves considerable expense. Because record keeping is inadequate and fragmented, this report represents a first attempt to document restoration activities for this region. Nevertheless, the evidence that activities emphasize coldwater fisheries enhancement in Michigan and Wisconsin, and water-quality improvement in Ohio, appears reasonable. Our estimate that $\$ 444$ million was spent on stream restoration and protection in these three states since 1990, with an average of only $11 \%$ of projects monitored, reinforces the point made by Bernhardt et al. (2005) in their national synthesis. Standardization of monitoring and record keeping and dissemination of findings are urgently needed to ensure that dollars are well spent and restoration effectiveness is maximized. 


\section{Implications for Practice}

- Stream restoration in the Midwest is increasing; yet, lack of project documentation and monitoring have inhibited the learning cycle.

- Since the early 1990s, total expenditures on stream restoration in the Upper Midwest region are approximately $\$ 444$ million.

- Project goals have emphasized improvements in instream habitat, riparian and bank condition, and water quality.

- Standardization of monitoring and record keeping and dissemination of findings are urgently needed to ensure that dollars are well spent and restoration effectiveness is maximized.

\section{Acknowledgments}

This study was part of the NRRSS, a working group supported by National Science Foundation's National Center for Ecological Analysis and Synthesis. We thank Margaret Palmer, Emily Bernhardt, and the members of the NRRSS working group for their input, and we thank the C.S. Mott Foundation and the University of Michigan for providing funding for the Upper Midwest portion of NRRSS. We thank all the data providers, and particularly recognize Paul Steen and Mike Wiley for providing us with the Michigan database. We thank Bob Hansis (Wisconsin Department of Natural Resources), Dan Mecklenburg (Ohio Department of Natural Resources), Paul Seelbach (Michigan Department of Natural Resources), Li Wang (formerly of Wisconsin Department of Natural Resources, currently Michigan Department of Natural Resources), and Gary Whelan (Michigan Department of Natural Resources) for providing an assessment of the representativeness of our data. NRCS data were provided by Economic Research Service, which compiled August 2005 CRP Contracts Database from the FSA. Some data are not available due to privacy restrictions required by the Farm Security and Rural Investment Act of 2002.

\section{LITERATURE CITED}

Albert, D. A. 1995. Regional landscape ecosystems of Michigan, Minnesota, and Wisconsin: a working map and classification. General Technical Report NC-178. U.S. Department of Agriculture, Forest Service, North Central Forest Experiment Station, St. Paul, Minnesota.

Alexander, G. G. 2005. The state of stream restoration in the Upper Midwest, U.S.A. M.S. thesis. University of Michigan, Ann Arbor.

Avery, E. L. 2004. A compendium of 58 trout stream habitat development evaluations in Wisconsin-1985-2000. Research Report 187. Wisconsin Department of Natural Resources, Madison.

Bednarek, A. T. 2001. Undamming rivers: a review of the ecological impacts of dam removal. Environmental Management 27:803-814.

Bernhardt, E. S., M. A. Palmer, J. D. Allan, G. Alexander, K. Barnas, S. Brooks, et al. 2005. Restoration of U.S. rivers-a national synthesis. Science 308:636-637.
Bohn, B. A., and J. L. Kershner. 2002. Establishing aquatic restoration priorities using a watershed approach. Journal of Environmental Management 64:355-363.

Covich, A. P., K. C. Ewel, R. O. Hall, P. E. Giller, W. Goedkoop, and D. M. Merritt. 2004. Ecosystem services provided by freshwater benthos. Pages $45-72$ in D. H. Wall, editor. Sustaining biodiversity and ecosystem services in soil and sediments. Island Press, Washington, D.C.

Cowx, I. G., and M. V. de Jong. 2004. Rehabilitation of freshwater fisheries: tales of the unexpected? Fisheries Management and Ecology 11:243-249.

Davis, N. M., V. Weaver, K. Parks, and M. J. Lydy. 2003. An assessment of water quality, physical habitat, and biological integrity of an urban stream in Wichita, Kansas, prior to restoration improvements (phase I). Archives of Environmental Contamination and Toxicology 44:351-359.

Downs, P. W., and G. M. Kondolf. 2002. Post-project appraisals in adaptive management of river channel restoration. Environmental Management 29:477-496.

Doyle, M. W., J. M. Harbor, C. F. Rich, and A. Spacie. 2000. Examining the effects of urbanization on streams using indicators of geomorphic stability. Physical Geography 21:155-181.

Freedman, P. L., V. K. S. Breidenbach, D. M. Infante, and A. S. Kumar. 2004. A retrospective look at watershed management, reflected through six WEF sponsored conferences. Watershed 2004; July 2004 (8). Water Environment Federation, Alexandria, Virginia.

Gilman, R. T., R. A. Abell, and C. E. Williams. 2004. How can conservation biology inform the practice of integrated river basin management? International Journal of River Basin Management 2:1-14.

Gleick, P. H. 2003. Global freshwater resources: soft-path solutions for the 21st century. Science 302:1524-1528.

Global Water Partnership. 2000. Integrated water resource management, TAC background paper 4. URL http://www.gwpforum.org [accessed 1 April 2005].

Hassett, B., M. Palmer, E. Bernhardt, S. Smith, J. Carr, and D. Hart. 2005. Status and trends of river restoration in the Chesapeake Bay watershed. Frontiers in Ecology and the Environment 3:259-267.

Hunt, R. L. 1988. A compendium of 45 trout stream habitat development evaluations in Wisconsin during 1953-1985. Technical Bulletin 162. Wisconsin Department of Natural Resources, Madison.

Jenkinson, R. G., K. Barnas, J. H. Braatne, E. S. Bernhardt, M. A. Palmer, J. D. Allan, and The National River Restoration Science Synthesis. 2006. Stream restoration databases and case studies: a guide to information resources and their utility in advancing the science and practice of restoration. Restoration Ecology 14:177-186.

Jungwirth, M., S. Muhar, and S. Schmutz. 2002. Re-establishing and assessing ecological integrity in riverine landscapes. Freshwater Biology 47:867-887.

Kondolf, G. M., and E. R. Micheli. 1995. Evaluating stream restoration projects. Environmental Management 19:1-15.

Laasonen, P., T. Muotka, and I. Kivijarvi. 1998. Recovery of macroinvertebrate communities from stream habitat restoration. Aquatic Conservation-Marine and Freshwater Ecosystems 8:101-113.

Larson, M. G., D. B. Booth, and S. A. Morley. 2001. Effectiveness of large woody debris in stream rehabilitation projects in urban basins. Ecological Engineering 18:211-226.

Lyons, J., and C. C. Courtney. 1990. A review of fisheries habitat improvement projects in warmwater streams, with recommendations for Wisconsin. Technical Bulletin No. 169. Wisconsin Department of Natural Resources, Madison.

Michener, W. K. 1997. Quantitatively evaluating restoration experiments: research design, statistical analysis, and data management considerations. Restoration Ecology 5:324-337.

Moerke, A. H., and G. A. Lamberti. 2004. Restoring stream ecosystems: lessons from a Midwestern state. Restoration Ecology 12:327-334. 
Murdock, J., D. Roelke, and F. Gelwick. 2004. Interactions between flow, periphyton, and nutrients in a heavily impacted urban stream: implications for stream restoration effectiveness. Ecological Engineering 22:197-207.

Oberle, S. L., and M. R. Burkart. 1994. Water-resource implications of Midwest agroecosystems. Journal of Environmental Quality 23:4-8.

Palmer, M. A., E. S. Bernhardt, J. D. Allan, G. Alexander, S. Brooks, J. Carr, et al. 2005. Standards for ecologically successful river restoration. Journal of Applied Ecology 42:208-217.

Poff, N. L., J. D. Allan, M. B. Bain, J. R. Karr, K. L. Prestegaard, B. D. Richter, R. E. Sparks, and J. C. Stromberg. 1997. The natural flow regime: a paradigm for river conservation and restoration. BioScience 47:769-784.

Pretty, J. L., S. S. C. Harrison, D. J. Shepherd, C. Smith, A. G. Hildrew, and R. D. Hey. 2003. River rehabilitation and fish populations: assessing the benefit of instream structures. Journal of Applied Ecology 40:251-265.
Roper, B. B., J. J. Dose, and J. E. Williams. 1997. Stream restoration: is fisheries biology enough? Fisheries 22:6-11.

Roth, N. E., J. D. Allan, and D. L. Erickson. 1996. Landscape influences on stream biotic integrity assessed at multiple spatial scales. Landscape Ecology 11:141-156.

Shields, F. D. Jr, S. S. Knight, N. Morin, and J. Blank. 2003. Response of fishes and aquatic habitats to sand-bed stream restoration using large woody debris. Hydrobiologia 494: 251-257.

Stanley, E. H. and M. W. Doyle. 2003. Trading off: the ecological effects of dam removal. Frontiers in Ecology and the Environment 1:15-22.

Steen, P. J. 2003. History and inventory of stream habitat improvements for the State of Michigan. M.S. thesis. University of Michigan, Ann Arbor.

White, R. G., and O. M. Brynildson. 1967. Guidelines for management of trout stream habitat in Wisconsin. Technical Bulletin No. 39. Wisconsin Department of Natural Resources, Madison.

Wissmar, R. C., and R. L. Beschta. 1998. Restoration and management of riparian ecosystems: a catchment perspective. Freshwater Biology 40:571-585. 